\title{
Small university departments threatened with closure
}

\section{London}

THE reorganization of teaching and research in UK universities, set in motion principally by restrictions on resources, shook the Earth sciences community earlier this year. Now it is the turn of chemistry and physics.

The two committees set up by the University Grants Committee (UGC) to plan the restructuring published their reports this week and both advocate concentration of available resources in fewer departments. But both also lay down strict guidelines to determine which departments should survive: those with at least 20 full-time staff and 200 fulltime students. Departments below this minimum level should close, merge with other departments or expand. There will probably be many interdepartmental mergers and some closures. At present there are 50 departments of chemistry and of physics: after restructuring there may be only 30 of each.

That size should be the key factor in determining the future of departments has raised the hackles of chemists and physicists in small departments. "Big is not necessarily beautiful" has been the common cry. And even those in large departments, the 'winners' according to the new reports, say size should not be the sole criterion.

Research income is one standard used to measure the success of a department. Statistics from the Committee of ViceChancellors and Principals show that the chemistry department of the University of Essex attracts more income than any other chemistry department in Britain, but it has only 130 full-time students. The chemistry department of the University of Bristol has three times as many students and only two-thirds the amount of income from research.

The response of the science community to the reports has been to urge the UGC not to implement the recommendations too rigidly. The physics committee acknowledges the benefits of small departments: they do come up with "bright ideas", and have good staffstudent relations. The chemistry committee is more reluctant in recommending the closure of small departments; an abrupt end is better than the present "demoralizing piecemeal attrition" due to lack of resources, it says. But among the benefits of having fewer and larger departments is their enhanced visibility and the increased probability of achieving international recognition. Both committees urge that every university should maintain some presence in each subject.

If the restructuring of other subjects proceeds according to size, the future of entire universities could be in doubt. Smaller universities tend to have smaller departments in several subjects. If government policy does not favour the closure of individual universities, this leaves a seemingly insoluble problem, says Professor Sam Edwards of the University of Cambridge, chairman of the physics review committee. Sir Peter Swinnerton-Dyer, chairman of the UGC, says that the future of chemistry and physics departments will not be planned without taking account of the effects on the university as a whole.

As well as advocating concentration of resources, which was bound to upset those to lose out, the committees tackle the most serious problems now facing academic science - lack of equipment and difficulty in attracting students and young academic staff. The committees both ask

for $£ 30$ million immediately for new equipment.

The chemistry report recommends that students be given greater opportunities to work in industry during vacations and that postgraduate training should include formal instruction and should not be slanted towards the needs of contemporary industry. It also says that basic research is in "serious danger" as resources are increasingly diverted into strategic and interdisciplinary research, and urges that it be protected.

The physics committee says that teaching should be more comprehensible to students and calls for a review of the difficulty of examinations, and for more highquality applied physics degree courses. Many academic physicists are depressed at what they see as a decline in physics research in Britain. An international review carried out for the committee by a policy studies group of the Royal Society shows that Britain's share of publications in physics declined from 7.7 per cent in 1973 to 5.7 per cent in 1984 .

Christine McGourty

\section{Soviet shuttle fails at last minute}

\section{Washington}

THE first flight of the Soviet space shuttle came within 51 seconds of lift-off on Saturday, 29 October, but a malfunction on the Baikonur launch pad caused a computer to abort the countdown.

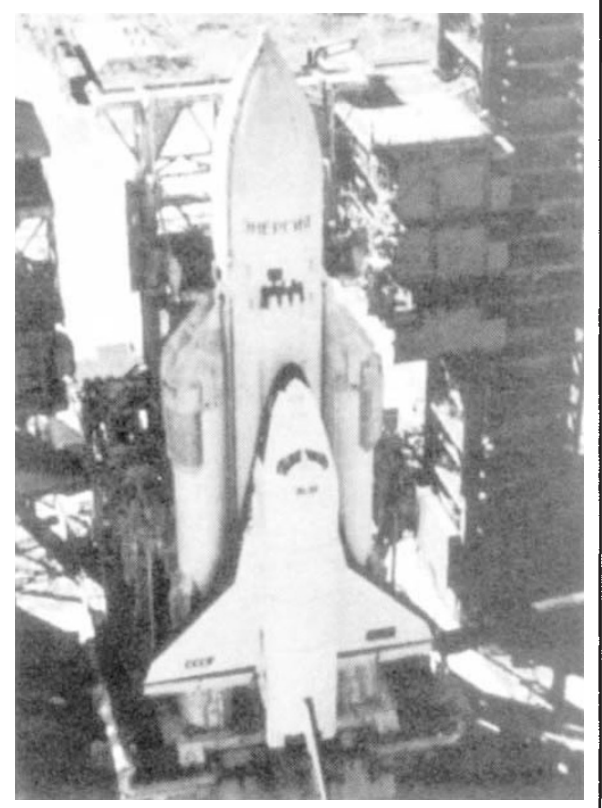

51 seconds to go - and Buran is grounded.

The flight has now been postponed indefinitely.

The setback came when the rocket was being freed from the servicing towers and the engines were being prepared for firing. The platform which carries the system that sets the rocket's gyroscopes failed to separate from the rocket to a safe distance. According to the Tass news agency, the fuel is being drained from the rocket and the engineers will then try to determine the cause of the problem.

The Soviet version of the space shuttle - called Buran, meaning snowstorm bears a striking resemblance to its US counterpart. It has the same delta-wing design for the orbiter and strap-on boosters, and it is attached to a large, external fuel tank. But many of the similarities are superficial, according to John Pike of the Federation of American Scientists, who has been studying the Soviet space programme. For example, the four booster rockets on the Soviet shuttle use a liquid rather than a solid propellant, and the main engines are integral with the fuel tank and are discarded after each mission.

The orbiter itself is said to have three engines for manoeuvring while in orbit, but these do not appear to be as large as those used by the US space shuttle orbiter. Buran is said to be able to carry a crew of seven, but the crew quarters appear to be more cramped aboard the Soviet shuttle, suggesting that it is to be used more as a ferry vehicle between Earth and an orbiting space station, rather than a standalone platform for manned space activities.

The payload capacity for the Soviet shuttle is around 60,000 pounds, a little less than the current US shuttle lift capacity. But the Energia booster system can be used to lift unmanned payloads as well, making it a more flexible vehicle.

The first mission was intended to be unmanned, completing two orbits of the Earth. 